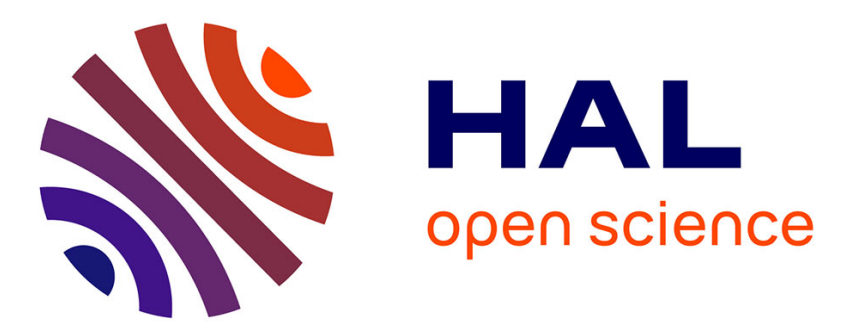

\title{
The influence of cerium ion concentrations on the characteristics of hybrid films obtained on AA2024-T3 aluminum alloy
}

Celia F. Malfatti, T. L. Menezes, Claudio Radtke, Julien Esteban, Florence Ansart, Jean-Pierre Bonino

\section{To cite this version:}

Celia F. Malfatti, T. L. Menezes, Claudio Radtke, Julien Esteban, Florence Ansart, et al.. The influence of cerium ion concentrations on the characteristics of hybrid films obtained on AA2024-T3 aluminum alloy. Materials and Corrosion / Werkstoffe und Korrosion, 2012, vol. 63, pp. 819-827. 10.1002/maco.201106070 . hal-00862238

\section{HAL Id: hal-00862238 \\ https://hal.science/hal-00862238}

Submitted on 16 Sep 2013

HAL is a multi-disciplinary open access archive for the deposit and dissemination of scientific research documents, whether they are published or not. The documents may come from teaching and research institutions in France or abroad, or from public or private research centers.
L'archive ouverte pluridisciplinaire HAL, est destinée au dépôt et à la diffusion de documents scientifiques de niveau recherche, publiés ou non, émanant des établissements d'enseignement et de recherche français ou étrangers, des laboratoires publics ou privés. 


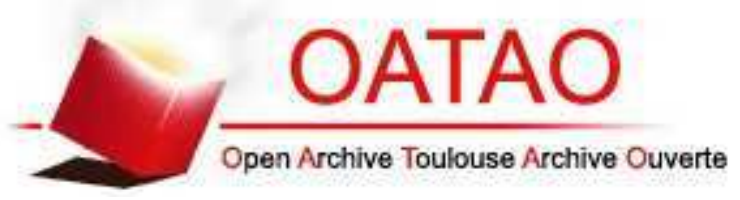

\section{Open Archive TOULOUSE Archive Ouverte (OATAO)}

OATAO is an open access repository that collects the work of Toulouse researchers and makes it freely available over the web where possible.

This is an author-deposited version published in : http://oatao.univ-toulouse.fr/ Eprints ID : 8703

To link to this article : DOI:10.1002/maco.201106070

URL : http://dx.doi.org/10.1002/maco.201106070

To cite this version : Malfatti, Celia F. and Menezes, T. L. and Radtke, Claudio and Esteban, Julien and Ansart, Florence and Bonino, JeanPierre. The influence of cerium ion concentrations on the characteristics of hybrid films obtained on AA2024-T3 aluminum alloy. (2012). Materials and Corrosion / Werkstoffe und Korrosion, vol. $63\left(n^{\circ}\right.$ 9). pp. 819-827. ISSN 0947-5117

Any correspondance concerning this service should be sent to the repository administrator: staff-oatao@ listes-diff.inp-toulouse.fr 


\title{
The influence of cerium ion concentrations on the characteristics of hybrid films obtained on AA2024-T3 aluminum alloy
}

\author{
C. F. Malfatti, T. L. Menezes*, C. Radtke, J. Esteban, F. Ansart and \\ J. P. Bonino
}

This work aimed to study the corrosion behavior of AA2024-T3 aluminum alloy substrates pre-treated with 3 glicidoxypropyltrimethoxysilane (GPTMS) silane layers doped with different cerium ion concentrations. The withdrawal speed of substrates from the sol was $20 \mathrm{~cm} \cdot \mathrm{min}^{-1}$. The hybrid films were obtained by dip-coating process and analyzed by scanning electron microscopy (SEM) and energy dispersive spectroscopy, Rutherford scattering spectroscopy (RBS), salt spray test, and electrochemical analyses. The correlation among the results obtained from different analyses was very good and indicated that the addition of $\mathrm{Ce}$ ion in the hybrid coating contributed to the corrosion resistance; however, for the high Ce ion concentration, the barrier effect of the hybrid films was deteriorated. The results obtained by RBS showed that the concentration of $\mathrm{Ce}$ ion in the hybrid film increased linearly with the concentration of $\mathrm{Ce}$ ion in the sol. Moreover, it was verified that, for the nominal concentration of $0.05 \mathrm{M} \mathrm{Ce}$ ion in the sol, the Ce atomic fraction increased in the hybrid film, while the $\mathrm{Si}$ atomic fraction reduced, indicating the possible modification on the silane network due to the incorporation of $\mathrm{Ce}$ ions.

\section{Introduction}

Due to the outstanding properties, such as low density, high conductivity, easy machining and corrosion resistance, aluminum and aluminum alloys have been extensively used in many technological applications, including car manufacturing, building materials, and aircraft industry [1-4]. However, its use has demanded higher corrosion resistance. Recent studies on the use of silanes as a surface primer to protect aluminum and aluminum alloys against corrosion have attracted the attention of researchers and industries. The use of corrosion inhibitors added to silane has also been reported $[5,6]$.

\section{F. Malfatti, T. L. Menezes}

Metallurgy Department, PPGEM, UFRGS, 91501-970, Porto Alegre (Brazil)

E-mail: tiagolm@gmail.com

C. Radtke

Chemistry Department, UFRGS, Porto Alegre (Brazil)

J. Esteban, F. Ansart, J. P. Bonino

Laboratoire Chimie des Matériaux Inorganiques et Energétiques, Institut Carnot CIRIMAT/Université Paul Sabatier - Bat. 2R1, 118 Route de Narbonne - 31062 Toulouse (France)
Several processes have been proposed to improve the corrosion resistance of aluminum alloys. The processes are usually based in three stages: pretreatment, primer, and finish coat (top-coating). The pre-treatment function is to protect the metal against corrosion and increase the adhesion between the metal and primer $[1,4,5]$. For many years the hexavalent chromate conversion coatings were used successfully as pretreatment for aluminum alloys. This process is functional and offers a high corrosion protection; however it employs hexavalent chromium compounds in its formulation. These compounds are considered a mutagenic and carcinogenic agent, which implies environmental restrictions for their use [1, 4]. In this way, alternatively, the hybrid films have been proposed as a pretreatment for aluminum alloys $[1,7,8]$.

Hybrid film based sol-gel coatings have been reported to provide good barrier properties because of the formation of dense -Si-O-Si-network. The hybrid films act as a physical barrier that hinders the penetration of aggressive species toward the metallic substrate $[1,8,9,10]$. The addition of corrosion inhibitors to hybrid films has been proposed with the aim of improving the corrosion performance of these films. In this case, the hybrid films act as a reservoir for inhibitors and release them to damaged and unprotected areas and prevent corrosion from taking place [4]. Among the salts of rare earths, cerium compounds 
are frequently used as inhibitors. Various organic and inorganic inhibitors were studied, and different authors demonstrated that rare earth salts, for example cerium nitrate, which are non-toxic and environmental friendly compounds can be promising for the chromates replacement [11-15]. Direct addition of cerium nitrate in the sol is possible to improve the anti-corrosion properties of hybrid coatings $[2,4,5,8,9,16-18]$.

However, some authors [19] proposed that cerium ions can be incorporated in the hybrid film, substituting some of the $\mathrm{Si}$ atoms, leading to the formation of a modified Si-O-Ce network. In the present study, the influence of cerium concentrations on the characteristics of hybrid films was evaluated. The AA2024-T3 aluminum alloy was coated by dip-coating process from a sol constituted of 3-gicidoxipropiltrimetoxisilano (GPTMS) and different concentrations of cerium nitrate $(0,0.01$, and $\left.0.05 \mathrm{~mol} \cdot \mathrm{L}^{-1}\right)$.

\section{Experimental}

AA2024-T3 aluminum alloy substrates were composed by (in wt\%) 3.8-5.0 Cu, 0.2-1.2 Mg, 0.4-1.0 Mn, 0.5-1.2 Si, <0.7 $\mathrm{Fe},<0.1 \mathrm{Cr}$. Each sample surface $(80 \mathrm{~mm} \times 42 \mathrm{~mm} \times 0.6 \mathrm{~mm})$ was cleaned and prepared using several steps; after acetone degreasing, a chemical pretreatment was performed as it follows: a 20-minute immersion in a $\mathrm{NaOH}$ solution $(\mathrm{pH}=9)$ maintained at $60^{\circ} \mathrm{C}$, followed by a rinsing with deionized water; a 5-minute acid immersion in an aqueous solution of $\mathrm{NaNO}_{3}$ at $\mathrm{pH}=0.95$ at room temperature. The samples were finally washed in ethanol and dried in air. The hybrid films were obtained on aluminum alloy, by dip-coating process, from a sol constituted by 3-GPTMS silanes and other precursors, with the addition of cerium nitrate at different concentrations $(0,0.01$, and $0.05 \mathrm{M})$. The withdrawal speed of substrates from the sol was $20 \mathrm{~cm} \cdot \mathrm{min}^{-1}$.

Scanning electron microscopy (SEM) was used to evaluate the hybrid film thickness, by cross section images. The equipment used was a JEOL JSM-5800 scanning microscope, with accelerating voltage $20 \mathrm{keV}$. The images were obtained by backscattered and secondary electrons, and analyzed with the ImageJ software to determine the film thickness.

The samples (Table 1) were characterized by Rutherford backscattering spectrometry (RBS) which was performed using a $2 \mathrm{MeV}$ He beam produced in the $3 \mathrm{MV}$ TANDEM accelerator of the Physics Institute-UFRGS. In all cases the incident direction of the beam was perpendicular to the sample surface, and the detection angle was at $165^{\circ}$ related to the direction of the beam.

The electrochemical behavior of the systems was evaluated by open circuit potentials (OCP) monitoring, potentiostatic polarization curves and electrochemical impedance spectroscopy (EIS) measurements in a $0.5 \mathrm{M} \mathrm{NaCl}$ solution $(\mathrm{pH}=6.0)$. A salt spray test was performed to evaluate the accelerated corrosion. For the electrochemical measurements, a three electrode electrochemical cell was used, consisting of a platinum counter electrode, a saturated calomel reference electrode and the sample $\left(0.626 \mathrm{~cm}^{2}\right)$, as a working electrode. The experimental apparatus used for the electrochemical investigation was a potentiostat (AUTOLAB PGSTAT 30) and a frequency response analyzer (FRA) system. The polarization curves were obtained in a scan range from $-200 \mathrm{mV}$ below the open circuit potential to $400 \mathrm{mV}$ above this potential, with a scan rate of $1 \mathrm{mV} \cdot \mathrm{s}^{-1}$. The data obtained from potentiostatic polarization measurements were treated with the software of GPES AUTOLAB for determining the corrosion current, corrosion potential and polarization resistance. EIS measurements were performed in potentiostatic mode at the OCP. The amplitude of the EIS perturbation signal was $10 \mathrm{mV}$, and the frequency studied ranged from $100 \mathrm{kHz}$ to $10 \mathrm{mHz}$. The systems were monitored for $72 \mathrm{~h}$ of immersion. Salt spray test was carried out according to ASTM B-117-03 standard test method [20]. The test was conducted for $168 \mathrm{~h}$ of exposure at $35^{\circ} \mathrm{C}$.

\section{Results and discussion}

\subsection{Morphological characterization and composition of the films}

The thicknesses of the hybrid film were determined from the analysis in cross-section of the coatings (Fig. 1), it was not observed a significant difference of hybrid films thicknesses for all the systems studied, and the thickness values determined were about $10.93 \pm 0.12 \mu \mathrm{m}$.

The results obtained, by Rutherford scattering spectroscopy (RBS) (Fig. 2), showed the relationship between the concentration of Ce ion in the sol and the atomic fraction of this ion in the film. It was also observed that the concentration of cerium in the film increased linearly with the concentration of cerium in the sol. However, for the nominal concentration of $0.05 \mathrm{M} C e$ ion in the sol at the same time the Ce atomic fraction increased in the hybrid film (Fig. 2a), the Si atomic fraction was reduced (Fig. 2b). These results indicated the possible modification on the silane network due to the incorporation of Ce ions, which replaced the $\mathrm{Si}$ atoms in this network, as it was suggested by other authors [19]. This effect was more important for high Ce ion atomic fraction in the hybrid film. Some authors [19] proposed that cerium ions can be incorporated in the hybrid film, substituting some of the $\mathrm{Si}$

Table 1. Description of the samples

\begin{tabular}{ll}
\hline Sample & Description \\
\hline AA2024-T3 & AA 2024-T3 aluminum alloy substrates were composed by (in wt\%) \\
AA2024-T3 WCe & $3.8-5.0 \mathrm{Cu}, 0.2-1.2 \mathrm{Mg}, 0.4-1.0 \mathrm{Mn}, 0.5-1.2 \mathrm{Si},<0.7 \mathrm{Fe},<0.1 \mathrm{Cr}$ ) \\
AA2024-T3 [0.01]Ce & AA2024-T3 aluminum alloy pretreated with silane without Ce addition \\
AA2024-T3 [0.05]Ce & AA2024-T3 aluminum alloy pretreated with silane and 0.01 M Ce addition \\
\hline
\end{tabular}


a)

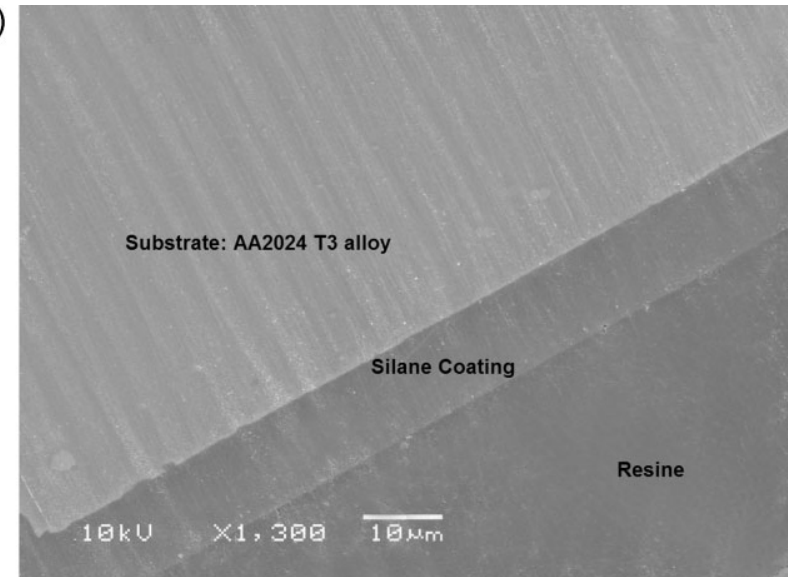

b)

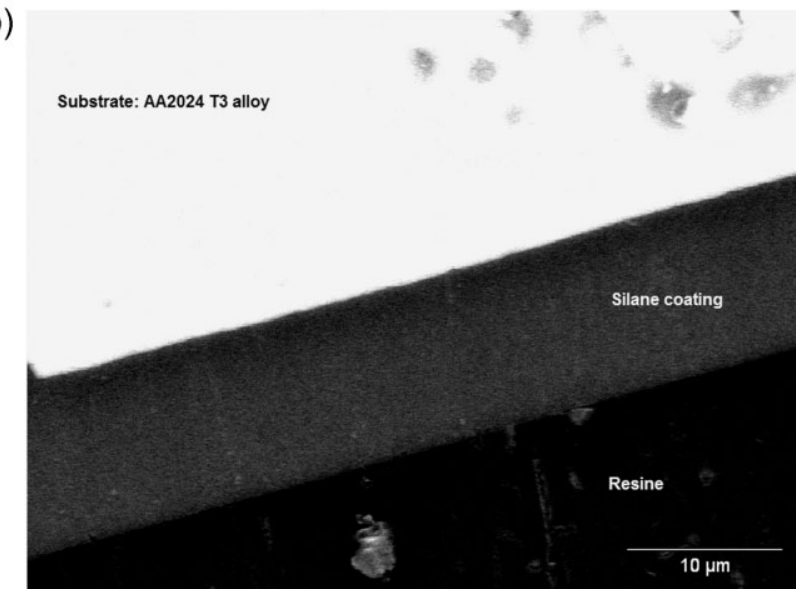

Figure 1. SEM for AA2024-T3 [0.01]Ce sample: a) secondary electrons, b) backscattered electrons

atoms, leading to the formation of a modified Si-O-Ce network. However, other authors [21], observed from the results obtained by DTA/TGA analyses that cerium concentration improved the xerogel densification and proposed that in the sol-gel silica network, cerium ions are probably located replacing $\mathrm{H}^{+}$ions in silanol groups $(=\mathrm{Si}-\mathrm{OH})$. In any of these cases the authors analyzed the composition of the hybrid film.

\subsection{Salt spray tests}

The salt spray test was used to evaluate the corrosion resistance of the samples. Figure 3 shows the general aspect of the AA2024 T3 sample treated with hybrid coating after $72 \mathrm{~h}$ (Fig. 3a, b, c) and after $168 \mathrm{~h}$ (Fig. 3d, e, f). For all the samples studied the first points of corrosion (pitting) were observed after $72 \mathrm{~h}$ of exposure, nevertheless, the AA2024-T3 [0.05] Ce sample (Fig. 3f) presented the highest pit density compared to the other samples. After $168 \mathrm{~h}$, corrosion products were visible on the substrate, indicating an intense corrosion of the protected metal, namely for AA2024T3W Ce and AA2024-T3 [0.05] Ce samples. It was also verified that the AA2024-T3 [0.05] Ce samples presented more damage compared to other samples. This behavior indicated that for the high Ce ion concentration, the barrier effect of the hybrid coatings was affected.

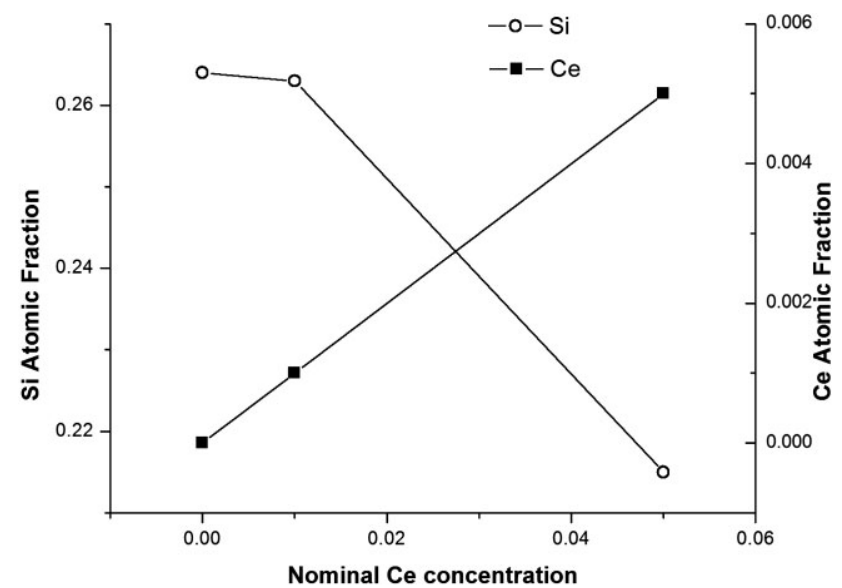

Figure 2. RBS analysis: Nominal Ce concentration in the sol versus the $\mathrm{Ce}$ atomic fraction in the coating and nominal Ce concentration in the sol versus Si atomic fraction in the coating

\subsection{Electrochemical characterization}

Figure 4 (a) and Fig. 4 (b) show the open circuit potential values and polarization curves for AA2024-T3 Al alloy untreated and post-treated with hybrid at different Ce ion concentrations. The results obtained from OCP test (Fig. 4(a)) showed that the samples coated with hybrid films presented potential values shifted to less active potential compared to the untreated AA2024T3 Al alloy. Furthermore, it was observed that the cerium concentration increase in the hybrid film displaced the OCP values to more negative potentials ( $E_{\text {corr }}$ AA2024-T3 W Ce $>E_{\text {corr }}$ AA2024-T3 [0.01]Ce $>E_{\text {corr }}$ AA2024-T3 [0.05]Ce). For the first minutes of immersion, the AA2024-T3 [0.05]Ce sample presented more active potential compared to other samples coated with hybrid film (Fig. 4(a)). However, at the end of $3600 \mathrm{~s}$, the potential developed by this system reached values similar to those observed for the AA2024-T3 [0.01]Ce sample. This phenomenon suggests that, in this case, the cerium ion acted as a corrosion inhibitor promoting the recovering of possible defects previously existent in this hybrid film obtained with 0.005 atomic fraction of Ce ion (Fig. 2). These results agree with the results obtained by other authors [19] which showed that the defect formation in the hybrid films exposes the metallic substrate and originates a localized anodic and cathodic activity. On the other hand, this behavior suggests that there is an unfavorable effect due to the Ce ions concentration increase in the hybrid film and indicate the possible modification on the silane network due to the incorporation of Ce.

From Table 2 and Fig. 4(b) it is possible to observe that the Ce ion addition modified the corrosion current $\left(I_{\text {corr }}\right)$ and polarization resistance $\left(R_{\mathrm{p}}\right)$ values; moreover, the Ce ion concentration effect is evidenced in the corrosion resistance of the hybrid films. For the AA2024-T3 [0.01]Ce samples (Ce ion concentration of 0.001 atomic fraction (Fig. 2)), it was verified that the addition of cerium ion promotes the increase of the $R_{\mathrm{p}}$ and the decrease of the $I_{\text {corr }}$ values, compared to the silane film without Ce. Besides, the AA2024-T3 [0.05]Ce samples [Ce ion concentration of 0.005 atomic fraction (Fig. 2)], the corrosion resistance is impaired, which can be observed by the increase of the $I_{\text {corr }}$ and the decrease 
a)

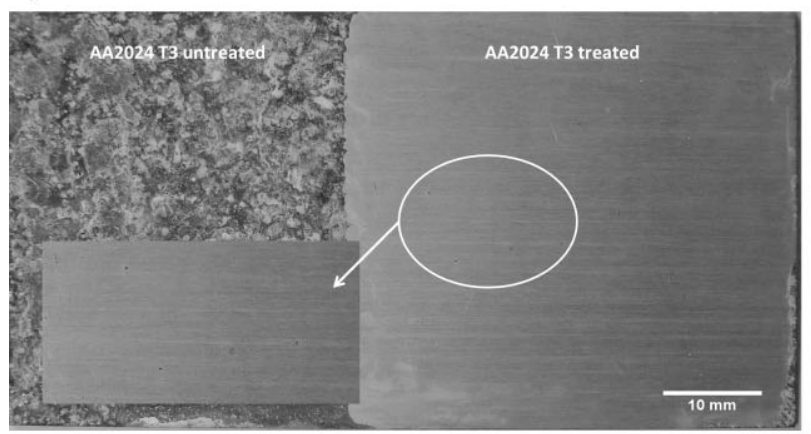

c)

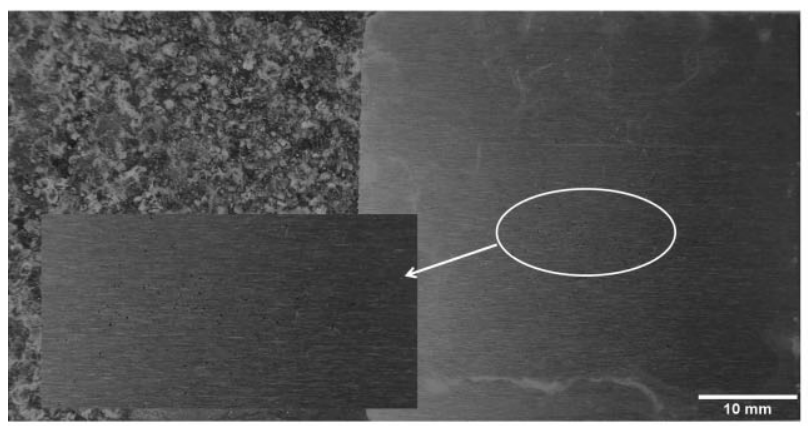

e)

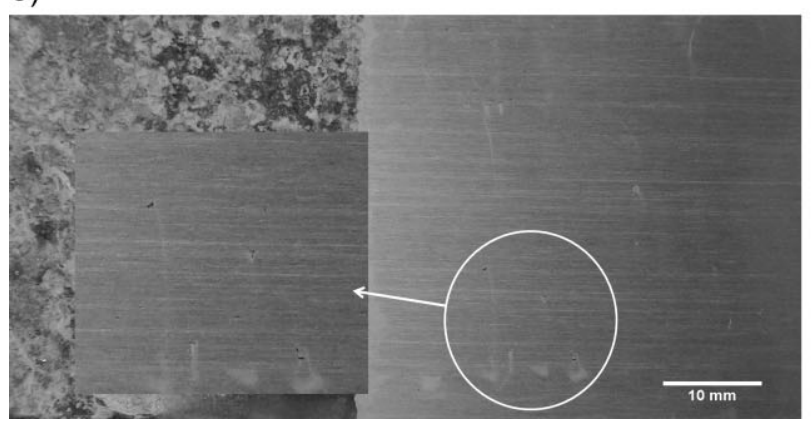

b)

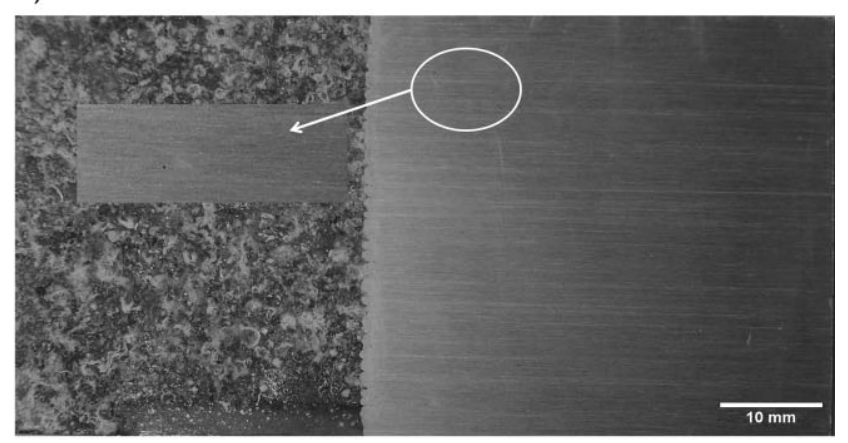

d)

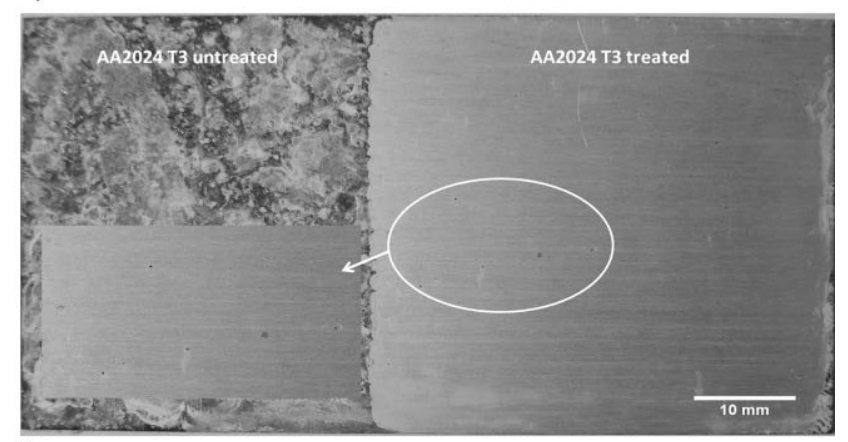

f)

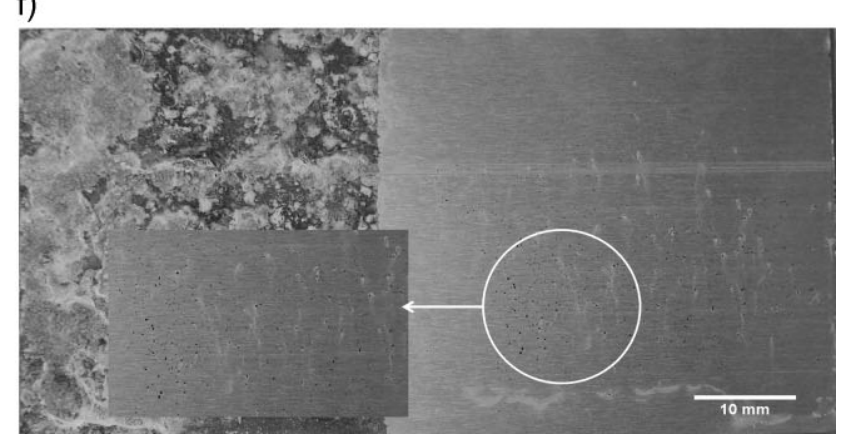

Figure 3. Optical micrographs of samples exposure after salt spray test: a) AA2024-T3 WCe after 72 h, b) AA2024-T3 [0,01] Ce after 72 h, c) AA2024-T3 [0.05] Ce after $72 \mathrm{~h}, \mathrm{~d})$ AA2024-T3 WCe after $168 \mathrm{~h}$, e) AA2024-T3 [0.01] Ce after $168 \mathrm{~h}, \mathrm{f}$ ) AA2024-T3 [0.05] Ce after $168 \mathrm{~h}$

of the $R_{\mathrm{p}}$ values. It seems that the presence of cerium ion in the hybrid films promoted the development of defects in the barrier formed by these films and in the present work this effect was more important when the concentration of Ce ion in the film reached 0.005 atomic fraction (Fig. 2).

The EIS was used in the present work to characterize the corrosion behavior of the developed coatings. A more detailed interpretation of the EIS measurements was performed by fitting the experimental plots using equivalent electrical circuits models which were proposed to simulate the electrochemical behavior of the coatings studied (Fig. 5). These models were based on the combination of resistances, capacitances, and other elements that should have a physical meaning, probably related to the electrochemical response of the system. Tables 3-6, present the electrical parameter values obtained by fitting the equivalent electrical circuit from the experimental EIS data, obtained for the AA 2024-T3 alloy untreated and post-treated with hybrid film for $72 \mathrm{~h}$ of immersion in a $0.5 \mathrm{M} \mathrm{NaCl}$ solution. In these circuits (Fig. 5), $R_{\mathrm{s}}$ represents the electrolyte resistance, $R(\mathrm{Sil})$ and CPE(Sil) represent, respectively, the resistance and a constant phase element associated with the hybrid film. In the same circuit, $R_{\mathrm{ox}}$ and $\mathrm{CPE}(\mathrm{Ox})$ represent the resistance and a constant phase element associated with the oxide layer formed between the hybrid film and the aluminum alloy. The same equivalent circuit model (Fig. 5-a) was proposed for the simulation of electrochemical behavior of AA2024T3 [0.05]Ce sample up to $24 \mathrm{~h}$ of immersion, after that, another equivalent circuit model (Fig. 5-b) was proposed, where $R(\mathrm{df})$ and $\mathrm{CPE}(\mathrm{df})$ were added and represent, respectively, the resistance and the constant phase element associated with the diffusion through the hybrid layer discontinuities.

It was observed the increase of the impedance values to the post-treated aluminum alloy (Fig. 6 and Fig. 7). This effect can occur due to the decrease of the corrosion rate of the substrate in the presence of the hybrid films and/or an enhanced barrier effect that increases the protection of the natural aluminum oxide film (Fig. 7-a and Fig. 7-b).

Figure 6-b shows the Bode plots of the samples after $72 \mathrm{~h}$ of immersion in a $0.5 \mathrm{M} \mathrm{NaCl}$ solution. As it can be seen, AA 

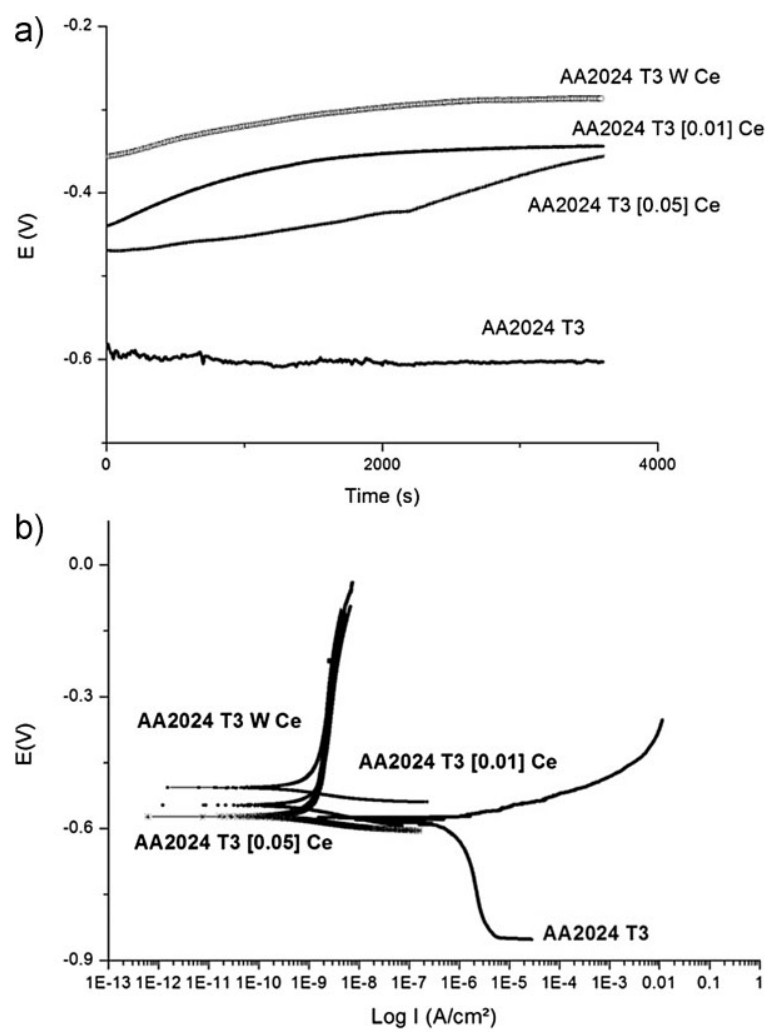

Figure 4. (a) $O C P$ diagram (in a $0.5 \mathrm{M} \mathrm{NaCl}$ solution) for untreated AA2024-T3 Al alloy, AA2024 T3 W Ce, AA2024 T3 [0.01]Ce and AA2024 T3 [0.05] Ce, (b) anodic and cathodic polarization curves (in a $0.5 \mathrm{M} \mathrm{NaCl}$ solution) for untreated AA2024-T3 Al alloy, AA2024 T3 WCe, AA2024 T3 [0.01] Ce and AA2024 T3 [0.05] Ce

2024T3W Ce and AA2024T3[0.01]Ce presented two-time constants, while the AA2024T3 [0.05]Ce system, presented threetime constants, that are clearly distinguished after $24 \mathrm{~h}$ immersion. For the AA2024T3 [0.05]Ce, this third time constant
(Fig. 6-b) is related to the corrosion process developed at the hybrid layer discontinuities.

The constant phase element of the hybrid film, at high frequencies $\left(10^{4} \mathrm{~Hz}\right)$, is responsible for the relaxation process, while the time constant at low frequencies $(0.1 \mathrm{~Hz})$ can be associated with the response of the aluminum oxide film resulting from the pre-treatment prior to the deposition of the hybrid film. Additionally, for the system AA2024-T3 [0.05]Ce (after $24 \mathrm{~h}$ of immersion), it was also observed, a phenomenon at middle frequencies $(100 \mathrm{~Hz})$, possibly related to the diffusion through the hybrid layer discontinuities.

The silane coating resistance $(R(\mathrm{Sil}))$ can be estimated by the Nyquist diagram from the semicircle diameter at high frequencies range. And for all the samples these values remained in the same order, although in all cases it is around $1-2 \mathrm{M} \Omega \mathrm{cm}^{2}$ for the first hours of immersion. After that, a decrease in the impedance values was observed, more significant for AA2024T3 [0.05]Ce system.

At low frequencies range, between 1 and $0.1 \mathrm{~Hz}$, a second time constant was observed and attributed to an oxide present on the metal/coating interface. This behavior was observed by other authors $[21,22]$. The high impedance values (around $10^{7} \Omega \mathrm{cm}^{2}$ ) obtained can be explained by the barrier effect of the hybrid films that prevents the penetration of the electrolyte through the film. During the corrosion test, the oxide resistance $(R(\mathrm{Ox}))$, for AA2024T3 [0.05]Ce system (Table 6), showed a lower value compared to other systems AA2024T3 [0.01]Ce (Table 5) and AA 2024T3 W Ce (Table 4) indicating the increase of permeability for the hybrid films of the AA2024T3 [0.05]Ce system associated with the degradation of the barrier effect of this film.

Figure 8 presents the evolution of hybrid films capacitance and resistance, which reflects the barrier properties degradation of hybrid films with the immersion time. The increase of the capacitance values and the gradual decrease of resistance values up to $72 \mathrm{~h}$ of immersion were observed for all the systems studied.

Table 2. Values of parameters obtained from the simulation of the Tafel slopes

\begin{tabular}{|c|c|c|c|c|}
\hline & AA2024-T3 & AA2024-T3 WCe & AA2024-T3 [0.01]Ce & AA2024-T3 [0.05]Ce \\
\hline$I_{\text {corr }}\left(\mathrm{A} \cdot \mathrm{cm}^{-2}\right)$ & $7.89 \mathrm{E}-7$ & 8.81E-10 & $8.46 \mathrm{E}-10$ & $1.07 \mathrm{E}-9$ \\
\hline$E_{\text {corr }}(\mathrm{V})$ & -0.586 & -0.513 & -0.564 & -0.579 \\
\hline$R_{\mathrm{p}}(\mathrm{Ohm})$ & $3.42 \mathrm{E}+3$ & $1.87 \mathrm{E}+6$ & $2.57 \mathrm{E}+6$ & $1.75 \mathrm{E}+6$ \\
\hline
\end{tabular}

a)

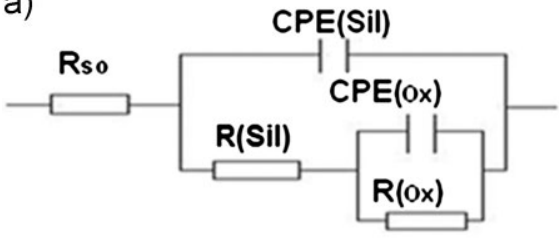

b)

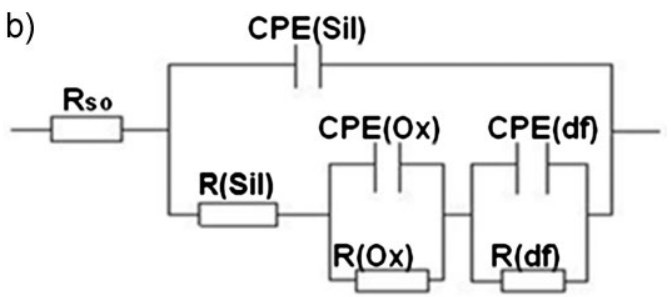

Figure 5. Equivalent electrical circuit used to fit the experimental EIS data obtained for AA2024-T3 aluminum alloy untreated and post-treated with hybrid films, in a $0.5 \mathrm{M} \mathrm{NaCl}$ solution: (a) for all systems along $72 \mathrm{~h}$ and AA2024-T3 [0.05]Ce before $24 \mathrm{~h}$ of immersion, (b) for AA2024-T3 [0.05]Ce between 24 and $72 \mathrm{~h}$ of immersion 
Table 3. Values of parameters obtained from the simulation of equivalent electrical circuit to experimental impedance diagrams for untreated AA2024-T3 aluminum alloy in a $0.5 \mathrm{M} \mathrm{NaCl}$ solution for $72 \mathrm{~h}$ of immersion

\begin{tabular}{|c|c|c|c|c|c|c|c|}
\hline Time (hours) & $\begin{array}{c}R_{\mathrm{s}} \\
\left(\Omega \cdot \mathrm{cm}^{2}\right)\end{array}$ & $\begin{array}{c}R \mathrm{ct} \\
\left(\Omega \cdot \mathrm{cm}^{2}\right)\end{array}$ & $\begin{array}{c}\text { CPEct-Q } \\
\left(\mathrm{Fcm}^{-2} \mathrm{~s}^{(\mathrm{n}-1)}\right)\end{array}$ & CPEct-n & $\begin{array}{c}R_{\mathrm{ox}} \\
\left(\mathrm{k} \Omega \cdot \mathrm{cm}^{2}\right)\end{array}$ & $\begin{array}{c}\text { CPEox-Q } \\
\left(\mathrm{Fcm}^{-2} \mathrm{~s}^{(\mathrm{n}-1)}\right)\end{array}$ & CPEox-n \\
\hline 1 & 8.96 & 9.10 & $0.543 \times 10^{-3}$ & 0.98 & 3.76 & $0.105 \times 10^{-4}$ & 0.88 \\
\hline 24 & 9.37 & 34.2 & $0.473 \times 10^{-3}$ & 0.74 & 3.70 & $0.317 \times 10^{-4}$ & 0.91 \\
\hline 48 & 9.35 & 39.2 & $0.488 \times 10^{-3}$ & 0.76 & 4.9 & $0.460 \times 10^{-4}$ & 0.89 \\
\hline 72 & 13.9 & 32.2 & $0.473 \times 10^{-3}$ & 0.75 & 4.27 & $0.510 \times 10^{-4}$ & 0.91 \\
\hline
\end{tabular}

Table 4. Values of parameters obtained from the simulation of the equivalent electrical circuit to experimental impedance diagrams for AA2024T3 WCe system in a $0.5 \mathrm{M} \mathrm{NaCl}$ solution for different immersion times

\begin{tabular}{lcccccc}
\hline $\begin{array}{l}\text { Time } \\
\text { (hours })\end{array}$ & $\begin{array}{c}R_{\mathrm{s}} \\
\left(\Omega \cdot \mathrm{cm}^{2}\right)\end{array}$ & $\begin{array}{c}R_{\mathrm{sil}} \\
\left(\mathrm{M} \Omega \cdot \mathrm{cm}^{2}\right)\end{array}$ & $\begin{array}{c}\text { CPEsil-Q } \\
\left(\mathrm{Fcm}^{-2} \mathrm{~s}^{(\mathrm{n}-1)}\right)\end{array}$ & CPEsil-n & $\begin{array}{c}R_{\mathrm{ox}} \\
\left(\mathrm{M} \Omega \cdot \mathrm{cm}^{2}\right)\end{array}$ & $\begin{array}{c}\text { CPEox-Q } \\
\left(\mu F \mathrm{~cm}^{-2} \mathrm{~s}^{(\mathrm{n}-1)}\right)\end{array}$ \\
\hline 1 & 145.5 & 1.16 & $0.337 \times 10^{-8}$ & 0.96 & 100 & 1.32 \\
24 & 246.2 & 0.227 & $0.613 \times 10^{-8}$ & 0.88 & 54.6 & 0.87 \\
48 & 292.8 & 0.145 & $0.101 \times 10^{-7}$ & 0.84 & 48.2 & 0.76 \\
72 & 573 & 0.123 & $0.150 \times 10^{-7}$ & 0.81 & 98.3 & 0.80 \\
\hline
\end{tabular}
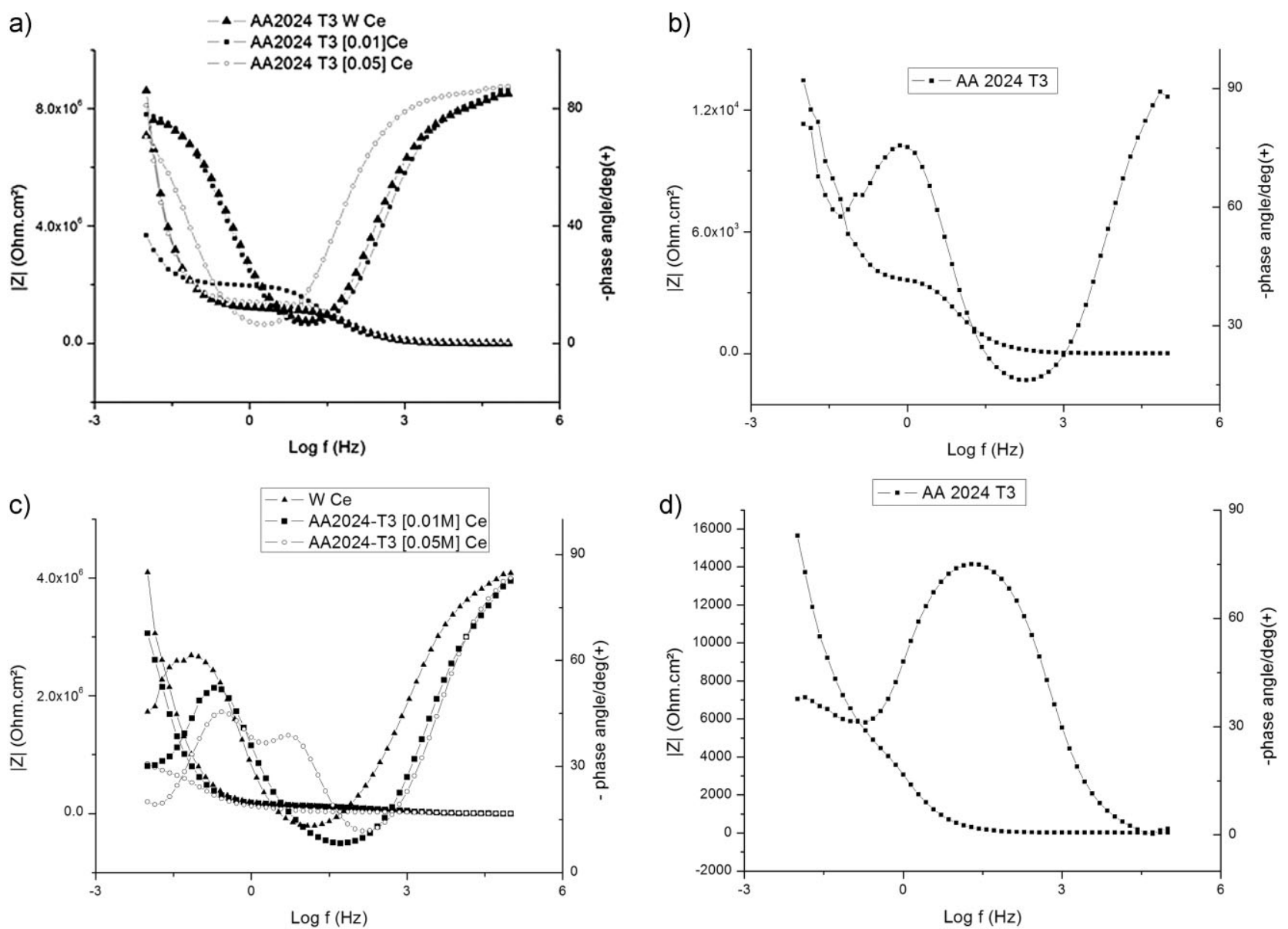

Figure 6. Bode diagrams obtained for AA2024 T3 W Ce, AA2024 T3 [0.01]Ce and AA2024 T3 [0.05]Ce pre-treated with hybrid films. (a) after 1 h of immersion in $0.5 \mathrm{M} \mathrm{NaCl}$ solution and (b) after $72 \mathrm{~h}$ of immersion in a $0.5 \mathrm{M} \mathrm{NaCl}$ solution. (c) AA $2024 \mathrm{~T} 3$ aluminum alloy after $1 \mathrm{~h}$ of immersion in 0.5 $\mathrm{M} \mathrm{NaCl}$ solution. (d) $\mathrm{AA} 2024 \mathrm{~T}_{3}$ aluminum alloy after $72 \mathrm{~h}$ of immersion in $0.5 \mathrm{M} \mathrm{NaCl}$ solution 

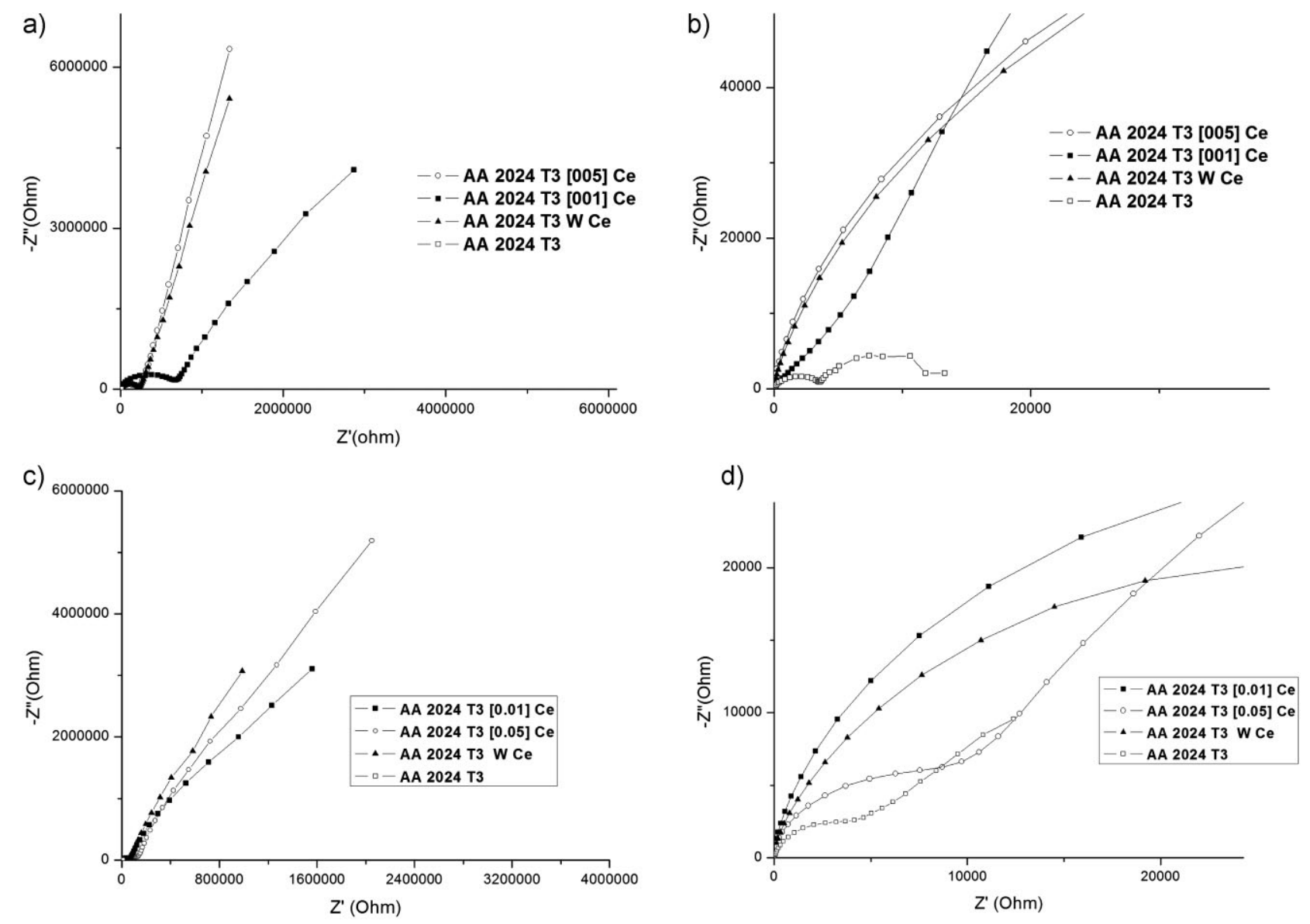

Figure 7. Nyquist diagrams (a) and (b) (zoom high frequencies) obtained after 1 h; Nyquist diagrams (c) and (d) (zoom high frequencies) obtained after $72 \mathrm{~h}$ of immersion in a $0.5 \mathrm{M} \mathrm{NaCl}$ solution for AA2024 T3, AA2024 T3 WCe, AA2024 T3 [0.01]Ce, AA2024 T3 [0.05]Ce pre-treated with hybrid films

Table 5. Values of parameters obtained from the simulation of the equivalent electrical circuit to experimental impedance diagrams for AA2024T3 [0.01]Ce system in a $0.5 \mathrm{M} \mathrm{NaCl}$ solution for different immersion times

\begin{tabular}{|c|c|c|c|c|c|c|c|}
\hline $\begin{array}{l}\text { Time } \\
\text { (hours) }\end{array}$ & $\begin{array}{c}R_{\mathrm{s}} \\
\left(\Omega \cdot \mathrm{cm}^{2}\right)\end{array}$ & $\begin{array}{c}R_{\mathrm{sil}} \\
\left(\mathrm{M} \Omega \cdot \mathrm{cm}^{2}\right)\end{array}$ & $\begin{array}{c}\text { CPEsil-Q } \\
\left(\mathrm{Fcm}^{-2} \mathrm{~s}^{(\mathrm{n}-1)}\right)\end{array}$ & CPEsil-n & $\begin{array}{c}R_{\mathrm{ox}} \\
\left(\mathrm{M} \Omega \cdot \mathrm{cm}^{2}\right)\end{array}$ & $\begin{array}{c}\text { CPEox-Q } \\
\left(\mu \mathrm{Fcm}^{-2} \mathrm{~s}^{(\mathrm{n}-1)}\right)\end{array}$ & CPEox-n \\
\hline 1 & 441 & 1.99 & $0.862 \times 10^{-8}$ & 0.83 & 100 & 3.94 & 0.85 \\
\hline 24 & 329 & 0.611 & $0.606 \times 10^{-8}$ & 0.84 & 25.61 & 2.31 & 0.86 \\
\hline 48 & 396 & 0.369 & $0.903 \times 10^{-8}$ & 0.80 & 106.3 & 2.32 & 0.90 \\
\hline 72 & 334 & 0.198 & $0.161 \times 10^{-8}$ & 0.78 & 71.8 & 3.96 & 0.88 \\
\hline
\end{tabular}

Table 6. Values of parameters obtained from the simulation of the equivalent electrical circuit to experimental impedance diagrams for AA2024-T3 [0.05]Ce system in a $0.5 \mathrm{M} \mathrm{NaCl}$ solution for different immersion times

\begin{tabular}{|c|c|c|c|c|c|c|c|c|c|c|}
\hline $\begin{array}{l}\text { Time } \\
\text { (hours) }\end{array}$ & $\begin{array}{c}R_{\mathrm{s}} \\
\left(\Omega \cdot \mathrm{cm}^{2}\right)\end{array}$ & $\begin{array}{c}R_{\text {sil }} \\
\left(\mathrm{M} \Omega \cdot \mathrm{cm}^{2}\right)\end{array}$ & $\begin{array}{c}\text { CPEsil-Q } \\
\left(\mathrm{Fcm}^{-2} \mathrm{~s}^{(\mathrm{n}-1)}\right)\end{array}$ & CPEsil-n & $\begin{array}{c}R_{\mathrm{ox}} \\
\left(\mathrm{M} \Omega \cdot \mathrm{cm}^{2}\right)\end{array}$ & $\begin{array}{c}\text { CPEox-Q } \\
\left(\mu \mathrm{Fcm}^{-2} \mathrm{~s}^{(\mathrm{n}-1)}\right)\end{array}$ & CPEox-n & $\begin{array}{c}R \mathrm{df} \\
\left(\mathrm{k} \Omega \cdot \mathrm{cm}^{2}\right)\end{array}$ & $\begin{array}{c}\text { CPEdf } \\
\left(\mu \mathrm{Fcm}^{-2} \mathrm{~s}^{(\mathrm{n}-1)}\right)\end{array}$ & CPEdf-n \\
\hline 1 & 605 & 1.36 & $0.357 \times 10^{-8}$ & 0.91 & 100 & 1.47 & 0.88 & - & - & - \\
\hline 24 & 679 & 0.255 & $0.106 \times 10^{-7}$ & 0.83 & 100 & 1.66 & 0.83 & - & - & - \\
\hline 48 & 208 & 0.048 & $0.234 \times 10^{-6}$ & 0.88 & 2.28 & 2.27 & 0.80 & 89.8 & $0.684 \times 10^{-8}$ & 0.75 \\
\hline 72 & 380 & 0.026 & $0.103 \times 10^{-4}$ & 0.85 & 0.863 & 2.82 & 0.77 & 153 & $0.909 \times 10^{-8}$ & 0.95 \\
\hline
\end{tabular}

System AA2024 T3 [0.01]Ce presented CPE(Sil) values around $8 \mathrm{nFcm}^{-2}$ and compared to the system AA2024 T3W Ce, the capacitance values showed a similar gradual increase throughout the test where both had values within the same order of magnitude. System AA2024 T3 [0.05]Ce showed values of $\mathrm{CPE}(\mathrm{Sil})$ in the same order as the other systems only during the first $48 \mathrm{~h}$ of testing. After that the $\mathrm{CPE}(\mathrm{Sil})$ values increased by three orders of magnitude compared to the other systems studied. 


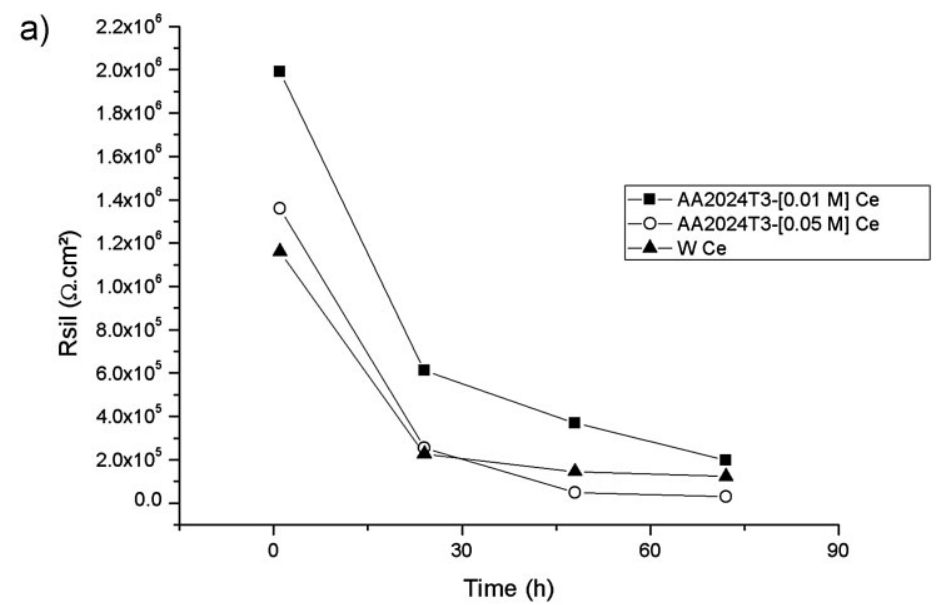

b)

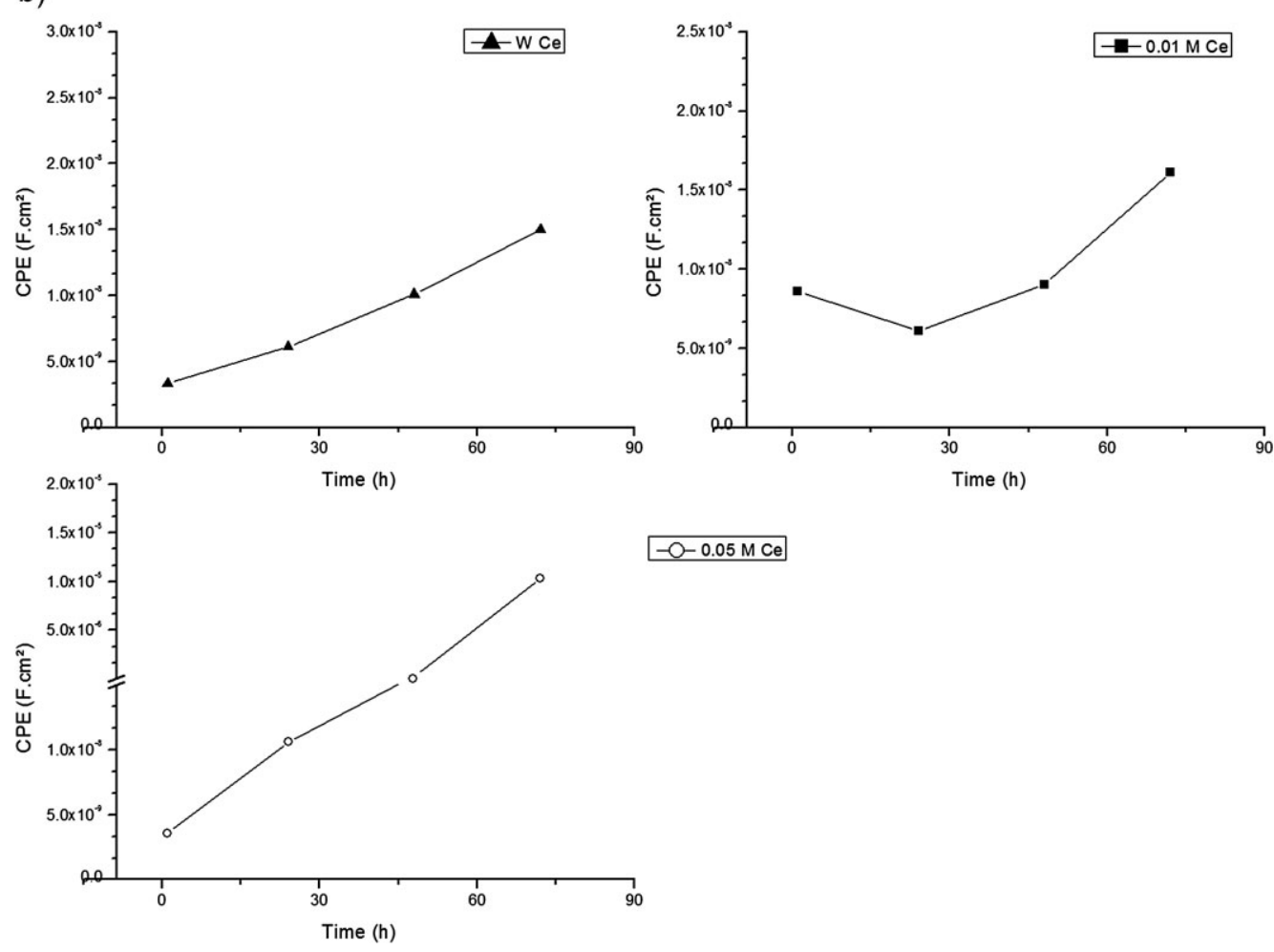

Figure 8. Evolution of the: (a) hybrid films resistance; (b) hybrid films constant phase element for AA2024 T3 WCe, AA2024 T3 [0.01]Ce, AA2024 T3 [0.05]Ce pre-treated with hybrid films (in a $0.5 \mathrm{M} \mathrm{NaCl}$ solution), with the immersion time

For all the systems studied, the drop of hybrid films resistance was attributed to the electrolyte penetration in the film. However the access of the species contained in the electrolyte induces localized activity followed by precipitation of insoluble products, which block the pores or defects at the hybrid film interface leading to a small recovery of the coating resistance. This behavior was observed for AA2024 T3 [0.05]Ce when the presence of a third phenomenon was observed associated with a resistance of diffusion through the hybrid layer discontinuities $(R(\mathrm{df}))$ from $48 \mathrm{~h}$ of immersion which increase for $72 \mathrm{~h}$ of immersion.

As it was mentioned before, AA2024 T3 [0.05]Ce system with $0.05 \mathrm{Ce}$ atomic fraction probably presented many discontinuities, demonstrating a poor barrier effect and this behavior is in agreement with the macroscopic results obtained from the salt spray tests (Fig. 3) and with the results obtained by other authors for the same hybrid films obtained on magnesium-based alloy AZ31 [22].

\section{Conclusion}

The atomic fraction of Ce ion in the films increases linearly with the Ce ion concentration in the sol and the results indicated that the Ce ion addition in the hybrid films confers an additional active corrosion protection by self-healing behavior which can be 
verified by the reduction of the corrosion rate compared to the hybrid film without Ce ion addition. However, high Ce ion atomic fraction in the silane film promoted the deterioration of barrier properties of the film, possibly due to the modification in the hybrid film network by the Ce ions incorporation.

Acknowledgements: The authors acknowledge the financial support from CNRS, CNPq, Finep and CAPES.

\section{References}

[1] K. A. Yasakau, M. L. Zheludkevich, O. V. Karavai, M. G. S. Ferreira, Prog. Org. Coat. 2007, 63, 352.

[2] S. M. Tamborim, A. P. Z. Maisonnave, D. S. Azambuja, G. E. Englert, Surf. Coat. Technol. 2008, 202, 5591.

[3] S. S. Pathak, A. S. Khanna, T. J. M. Sinha, Prog. Org. Coat. 2007, 60, 211.

[4] V. Palanivel, Y. Huang, W. J. V. Ooij, Prog. Org. Coat. 2005, 53, 153.

[5] A. M. Cabral, W. Trabelsi, R. Serra, M. F. Montemor, M. L. Zheludkevich, M. G. S. Ferreira, Corros. Sci. 2006, 48, 3740 .

[6] L. M. Palomino, P. H. Suegama, I. V. Aoki, M. F. Montemor, H. G. De Melo, Corros. Sci. 2009, 51, 1238.

[7] D. Zhu, W. J. V. Ooij, Electrochem. Acta 2004, 49, 1113.

[8] W. Trabelsi, E. Triki, L. Dhouibi, M. G. S. Ferreira, M. L. Zheludkevich, M. F. Montemor, Surf. Coat. Technol. 2006, 200,4240 .
[9] A. M. Cabral, R. G. Duarte, M. F. Montemor, M. G. S. Ferreira, Prog. Org. Coat. 2005, 54, 322.

[10] N. Pirhad Tavandashti, S. Sanjabi, T. Shahrabi, Mater. Corros. 2011, 62, 411.

[11] B. R. W. Hinton, L. Wilson, Corros. Sci. 1989, 29, 967.

[12] M. Bethencourt, F. J. Botana, M. J. Cano, M. Marcos, Appl. Surf. Sci. 2004, 238, 278.

[13] A. J. Aldykewicz, H. S. Isaacs, A. J. Davenport, J. Electrochem. Soc. 1995, 142, 3342.

[14] A. Decroly, J. P. Petitjean, Surf. Coat. Technol. 2005, 194(1), 2005.

[15] T. A. Markley, J. I. Mardel, A. E. Hughes, B. R. W. Hinton, A. M. Glenn, M. Forsyth, Mater. Corros. 2011, 62, 836.

[16] C. Motte, N. Maury, M. G. Olivier, J. P. Petitjean, J. F. Willem, Surf. Coat. Technol. 2005, 200, 2366.

[17] X. Yu, L. Yingjie, L. Sha, J. Rare Earths 2007, 25, 193.

[18] L. E. M. Palomino, P. H. Suegama, I. V. Aoki, Z. Paszti, H. G. De Melo, Electrochim. Acta 2007, 52, 7496.

[19] M. F. Montemor, M. G. S. Ferreira, Electrochim. Acta 2007, 52,7486

[20] ASTM B-117-03: Standard Practice for Operating Salt Spray (Fog) Apparatus. American Society for Testing and Materials 2003.

[21] M. Garcia-Heras, A. Jimenez-Morales, B. Casal, J. C. Galvan, S. Radzki, M. A. Villegas, J. Alloys Compd. 2004, 380, 219.

[22] A. F. Galio, S. V. Lamaka, M. L. Zheludkevich, L. F. P. Dick, I. L. Müller, M. G. S. Ferreira, Surf. Coat. Technol. 2010, 204, 1479. 